\title{
COMPARING THE IMPACT OF VOCATIONAL REHABILITATION AND THE EMPLOYMENT OF PERSONS WITH DISABILITIES ON COMPANIES: ANALYSIS OF EXISTING RESEARCH
}

\author{
Boris Miethlich \\ Comenius University in Bratislava, Faculty of Management \\ Odbojárov 10 \\ Bratislava, 820 05, Slovakia \\ boris.miethlich@fm.uniba.sk
}

\begin{abstract}
The constant above-average unemployment rate of people with disabilities (PWD) and the failure of government measures to date indicate the need for companies to address this issue themselves. A reliable understanding of the effects and implications of employment of PWD and vocational rehabilitation for strategic corporate management is therefore required to specifically promote the integration of PWD into the labor market. This paper compares the impacts of the two concepts from a management perspective. A literature review was conducted to collect and analyze the state of research for similarities and differences regarding the categories government policies, corporate social responsibility (CSR), benefits and consequences for companies and business opportunities using a summary content analysis. The results suggest that the effects on companies and the resulting implications are identical, at least over a longer period. The employment of PWD, as well as vocational rehabilitation, can be a key to attracting customers with disabilities and thus allowing to enter new market segments.
\end{abstract}

Keywords: vocational rehabilitation, employment of persons with disabilities, CSR, strategic management

\section{Introduction}

There are persons with disabilities (PWD) who are not affected in their working life or at their workplace. However, there are impairments or handicaps that force people to switch jobs or occupations or to give up employment fully [1]. It is estimated that in each country 10 to 20 percent of the population is affected by disabilities [2]. Despite all efforts (e.g., legal provisions, anti-discrimination, equal treatment), PWD continues to be affected by unemployment to an above-average extent [3]. At the same time, the PWD segment is a mostly untapped market for products and services [2] as well as an enormous untapped workforce potential [4]. If companies want to exploit this potential and be successful in this market segment, this requires, as in any other segment, a clear understanding of the needs of the market. Only if customer needs are met effectively, profitably and better than by competitors, a genuine competitive advantage can be created [5]. A commitment to vocational rehabilitation and employment of PWD can help develop a better understanding of the needs and concerns of customers with disabilities [6]. So far companies seem to ignore the potential of PWD as customers and as employees [7], although there is some empirical evidence that PWD employment can bring many benefits to companies [8].

Vocational rehabilitation can be understood as a variant of PWD employment. However, it differs from the employment of PWD in several respects. For example, it can be assumed that a person with a disability knows what adjustments are required at the workplace or what aids are needed and how to optimally use them.

In the context of vocational rehabilitation, performance must first be trained and tested, which takes some time due to the adaption of the work process, required aids and testing the optimal adjustments to the workplace. The employment of PWD as an actual employment relationship tends to be long-term, whereas vocational rehabilitation in companies represents a limited period of several months.

This article aims to briefly present and compare the current state of research on the effects of PWD employment and vocational rehabilitation on companies. This article shows the similarities and differences between the two concepts and derives findings for strategic corporate management.

\subsection{Employment of PWD}

The integration of PWD in the company must be understood as a standardized process aimed at promoting employment under the same conditions as other employees [9]. PWD cannot simply be equated with other disadvantaged groups as part of "diversity". Diversity management approaches seem to be too limited and cannot promote equality and equal opportunities for PWD [10]. The main element of proactive employment of PWD and their integration into the company is the reduction of mental and physical barriers within the company [11]. A company's commitment to PWD employment can already significantly reduce barriers [12]. In principle, PWD employment is about adapting each job individually to the needs of PWD and the business context [3]. Individual adjustments to the workplace and working environment according to the disability [12] or individual aids are therefore often necessary [3]. However, adjustments to the job profile [12] or the general conditions may also be necessary. It includes the need for irregular, adapted or flexible working hours or the possibility of telecommuting [13]. PWD face wide-ranging barriers in recruitment and employment [3]. To increase the number of PWD, companies should take disabilities already into account when recruiting [14]. The procedures and techniques of job interviews should be reviewed to determine to what extent they limit the applicant's ability to demonstrate the required qualifications [3]. 
The employment of PWD and therefore the use of the potential of PWD as a workforce requires open-minded companies that are prepared to reduce mental and physical barriers in the company.

\subsection{Vocational Rehabilitation}

After an accident or serious illness, the return to work can become difficult or even impossible due to long incapacity to work or permanent restrictions. In this case, vocational rehabilitation [15] takes place in parallel or after medical rehabilitation. Vocational rehabilitation enables persons with a temporary, impending or permanent disability to access, return to or remain in a job [16].

The vocational rehabilitation insurers accompany the person concerned in this process and cooperate with companies and specialized institutions (e.g., sheltered workshops, social enterprises for work integration, employment support). The inclusion of companies is the most efficient and effective option in vocational rehabilitation [15]. Often, however, there are no suitable alternatives with the previous employer and the person concerned is dependent on being given a chance despite possible impairments in another company.

The insurance carriers provide a full range of employment and training services for PWD seeking jobs and for companies seeking workers [17]. This may also include additional measures such as vocational assessment, vocational reorientation, retraining, counseling, workplace guidance and counseling, ergonomic adjustments at the workplace, functional recovery programs as well as psychosocial interventions and other forms of preparation for the return to work [18]. These vocational rehabilitation interventions are applied almost identically to people with congenital or developmental disabilities who want to enter the labor market for the first time [15], but also to PWD who return to work or change jobs after a long absence.

When companies become involved in vocational rehabilitation, they are faced with a tension between assuming social responsibility and fulfilling their operational goals [19].

\section{Methods}

The research was conducted by searching the databases Web of Science and SCOPUS for published literature since 2000 in the subject areas of business, economics, and management using the following keywords: vocational rehabilitation, occupational rehabilitation, return-to-work, disability management, and employment of persons with disabilities. Additionally, the reference lists of all previously selected articles were checked to find further studies. The titles, abstracts, and keywords of papers were scanned to identify papers related to vocational rehabilitation and employment of persons with disabilities. For the in-depth analysis, English articles published in peer-reviewed journals, conference proceedings or books describing the business management aspects of the topic were selected.
The selected literature was evaluated regarding explicit similarities and differences using a deductive content analysis [20]. The coding was carried out according to the following categories: government policies, CSR, benefits and consequences for companies, and business opportunities. In the case of multiple references, the most recent source was cited.

\section{State of Research}

The knowledge of vocational rehabilitation is relevant for the employment of PWD [6]. However, the effects of vocational rehabilitation [21] and the employment of PWD have hardly been investigated from an organizational management perspective [6].

Lindsay et al. (2018) have compiled the advantages and effects of PWD employment mentioned in various studies in extensive systematic literature analysis. A total of 6,176 studies from the last two decades were examined. Of these, only 39 studies could be identified which dealt at least partially with the advantages and effects on companies employing PWD [8].

There are a few studies regarding the effects of vocational rehabilitation on companies which in principle all concentrate on the same few familiar aspects [22]. For example, various studies show that vocational rehabilitation reduces disability rates and overall health costs [23]. Nevertheless, due to the wide variety of disabilities and intervention possibilities, it is almost impossible to determine cost-effectiveness or cost benefits accurately [22]. Accordingly, no international consensus has yet been reached on the methodology of vocational rehabilitation as well as its effectiveness and efficiency [24]. CSR literature has also paid little attention to both vocational rehabilitation and the employment of PWD [25].

There is no comprehensive understanding of how the employment of PWD or vocational rehabilitation affects companies. There is a lack of in-depth analysis and knowledge on how competitive advantages can be derived and the implications for strategic corporate management.

\section{Results}

The results of the deductive content analysis are described below according to the coded categories: government policies, CSR, benefits and consequences for companies, and business opportunities.

\subsection{Government Policies}

Legislation alone is insufficient for the economic integration of PWD. Companies rarely implement legal directives and guidelines and do not claim government support [26]. The same applies to vocational rehabilitation. In addition, cooperation between insurers and companies is often inadequate and hampered by general problems [27]. In most countries, PWD employment and vocational rehabilitation are exclusively voluntary social commitments on the part of companies. Nevertheless, in 
many countries, the political aim is to reduce the number of recipients of disability pensions, primarily by increasing the eligibility criteria. Therefore, vocational rehabilitation will become even more strategically important for insurance providers and in politics. The need for companies that carry out vocational rehabilitation and are open and positive towards PWD will become even greater [4].

\subsection{CSR}

The promotion of PWD employment and vocational rehabilitation serves as an added value for a company's social responsibility program. On the one hand, the commitment serves society and the company is regarded as a good "corporate citizen". On the other hand, it creates a positive image and makes disability-friendly values explicit in the workplace [28].

The constant above-average unemployment rate of PWD and the failure of government measures indicate the need for companies to address this issue in the context of CSR [25].

Occupational safety and health is already an important and central element of CSR which is taken into account in all CSR tools and instruments. However, if an employee becomes ill or has an accident and subsequently needs support in returning to work or vocational rehabilitation, this is rarely part of the CSR strategy [29]. The employment of PWD is also rarely part of the CSR strategy in business practice [30].

The employment of PWD and vocational rehabilitation are an essential element of social responsibility towards the employees and towards society [29].

\subsection{Benefits and Consequences for Companies}

The employment of PWD can bring various advantages for companies, such as employee loyalty and motivation, company image, various customers, customer loyalty and satisfaction, innovation, productivity, work ethic, safety, inclusive work culture [8]. Additionally, personnel costs can be reduced by exploiting state subsidies or tax benefits [30].

Vocational rehabilitation can bring advantages to companies. These advantages can be divided into three categories: Increasing productivity, reducing personnel costs and maintaining the return on human capital. The faster an impaired employee can return to work, the less disruption will be caused in the work processes. If an affected employee can be retained in the company, the fluctuation rate decreases and therefore also the personnel costs (e.g., recruitment, selection, employment and training of a replacement employee). Losing an employee due to illness or accident reduces the "return-oninvestment" in the employee's previous investment in formal and practical training [31]. Overall, vocational rehabilitation makes a positive contribution to the success of the company [21].
After successful vocational rehabilitation, affected employees are above-average committed and loyal [31]. A positive social reaction to disability in the workplace reduces the stigma and threat of job loss associated with it. Employees who learn how the company cares for sick or injured colleagues seem to have better resilience. Studies also indicate that the existence of disability management or vocational rehabilitation program in a company is associated with fewer work-related burnout cases and an improved corporate culture as well as a positive influence on the job satisfaction of the affected persons and their colleagues [32]. Vocational rehabilitation offers a great opportunity of recruiting and retaining employees [29].

Employment of PWD brings similar advantages. PWD are very loyal employees and change jobs less often, thus reducing staff turnover in the company. PWD are very dedicated employees and have higher productivity in comparison. PWD are an integral part of a diverse workforce [33]. Also, the employment of PWD seems to increase psychological safety at work, which can lead to a higher motivation of all employees, less staff turnover, higher overall profitability and accordingly to a competitive advantage [34].

The employment of PWD offers companies a competitive advantage in the form of a source of qualified, committed and loyal employees [35]. This untapped pool of applicants can also be a solution to a future shortage of skilled workers [36]. Moreover, the integration of PWD into the company improves the corporate culture and strengthens the employer brand [37]. There are also benefits to be gained from CSR, particularly through an improved corporate image [38].

The benefits seem to outweigh the costs in both PWD employment and vocational rehabilitation.

\subsection{Business Opportunities}

Companies should respond to the needs of customers with disabilities, as they may need specially designed products and services to be able to benefit from the offer [39]. A company can develop a comprehensive understanding of the needs and concerns of customers with disabilities through a commitment to vocational rehabilitation or the employment of PWD [6]. This commitment can increase awareness of disability among employees [8], which in turn promotes innovation [36] and the development of "designed-for-all" products and services [38]. Additionally, employment of PWD is in itself an opportunity to attract and retain socially responsible customers and customers with disabilities [8].

The employment of PWD and vocational rehabilitation can minimize social and health costs for society in the long term and secure the professional future of those affected. Companies that commit themselves can generate an actual "shared value" since the prosperity of society is increased which will benefit the company in return [29]. 


\section{Conclusion}

The analysis of the state of research leads to the conclusion that the effects on companies by the employment of PWD and vocational rehabilitation are identical, at least when observed over a longer period.

Hence, the employment of PWD, as well as the vocational rehabilitation, allows a company to benefit from the resulting multiple advantages. Further, the resulting sensitivity to disability allows companies to develop products and services for PWD, which could open up new market segments.

From a business point of view, both concepts have hardly been researched. There is still a need for research into a solid understanding of the effects on companies and the implications for strategic corporate management. Only then can the employment of PWD and vocational rehabilitation be specifically promoted by companies themselves.

\section{References}

[1] Niehaus, M., Behinderte auf dem Arbeitsmarkt, Frankfurt, Campus Verlag, 1997, 28-53.

[2] Collins, A. B., Opportunities and Obligations in Dealing with the Disabled Staff and Customers in Hospitality Industry, Tourism Management in the 21st Century, pp. 157-178, 2007.

[3] Markel, K. S., Barclay, L. A., Addressing the Underemployment of Persons with Disabilities: Recommendations for Expanding Organizational Social Responsibility. Employee Responsibilities and Rights Journal, Vol. 21, pp. 305-318, 2009.

[4] Buys, N., Matthews, L. R., Randall, C., Contemporary vocational rehabilitation in Australia, Disability and rehabilitation, Vol. 37, No. 9, pp. 820-824, 2015.

[5] Papulova, E., Papulova, Z., Competitive strategy and competitive advantages of small and midsized manufacturing enterprises in Slovakia. E-Leader, 2006.

[6] Seino, K., Nomoto, A., Takezawa, T., Boeltzig-Brown, H., Handbook of Research on Human Factors in Contemporary Workforce Development, Hershey, IGI Global, 2017, 333-356.

[7] Lengnick-Hall, M. L., Gaunt, P. M., Kulkarni, M., Overlooked and underutilized: People with disabilities are an untapped human resource, Human Resource Management, Vol. 47, No. 2, pp. 255-273, 2008.

[8] Lindsay, S., Cagliostro, E., Albarico, M., Mortaji, N., Karon, L., A Systematic Review of the Benefits of Hiring People with Disabilities, Journal of Occupational Rehabilitation, pp. 1-22, 2018.

[9] Munduate, L., Di Marco, D., Martinez-Corts, I., Arenas, A., Gamero, N., Rebuilding the social dialogue and promoting inclusive organizations, Papeles Del Psicólogo, Vol. 35 No. 2, pp. 122-129, 2014.

[10] Woodhams, C., Danieli, A., Disability and diversity a difference too far?, Personnel Review, Vol. 29 No. 3, pp. 402-417, 2000.

[11] Hidegh, A. L., Csillag, S., Toward 'mental accessibility': changing the mental obstacles that future
Human Resource Management practitioners have about the employment of people with disabilities, Human Resource Development International, Vol. 16, No. 1, pp. 22-39, 2013.

[12] Schur, L., Kruse, D., Blanck, P., Corporate Culture and the Employment of Persons with Disabilities, Behavioral Sciences and the Law, Vol. 23, No. 1, pp. 3-20, 2005.

[13] Schur, L., Nishii, L., Adya, M., Kruse, D., Bruyère, S. M., Blanck, P., Accommodating Employees with and without Disabilities, HR Science Forum, Vol. 53, No. 4, pp. 593-621, 2014.

[14] Segovia-San-Juan, A. I., Saavedra, I., Fernandez-deTejada, V., Analyzing Disability in Socially Responsible Companies, Social Indicators Research, Vol. 130, No. 2, pp. 617-645, 2017.

[15] Gobelet, C., Franchignoni, F., Vocational Rehabilitation, Paris, Springer, 2006.

[16] Waddell, G., Burton, A. K., Kendall, N. A. S., Vocational rehabilitation - what works, for whom, and when?, London, TSO, 2008.

[17] Chi, C. G. Q., Qu, H., Integrating persons with disabilities into the work force: A study on employment of people with disabilities in foodservice industry, International journal of hospitality \& tourism administration, Vol. 4, No. 4, pp. 59-83, 2003.

[18] Marnetoft, S. U., Selander, J., Bergroth, A., Ekholm, J., Factors associated with successful vocational rehabilitation in a Swedish rural area, Journal of Rehabilitation Medicine, Vol. 33, No. 2, pp. 71-78, 2001.

[19] Seing, I., MacEachen, E., Ekberg, K., Ståhl, C., Return to work or job transition? employer dilemmas in taking social responsibility for return to work in local workplace practice, Disability and rehabilitation, Vol. 37, No. 19, pp. 1760-1769, 2015.

[20] Mayring, P., Qualitative Inhaltsanalyse, Weinheim, Beltz, 2015.

[21] Tompa, E., De Oliveira, C., Dolinschi, R., Irvin, E., A systematic review of disability management interventions with economic evaluations, Journal of Occupational Rehabilitation, Vol. 18, No. 1, pp. 16-26, 2008.

[22] Howard-Wilsher, S., Irvine, L., Fan, H., Shakespeare, T., Suhrcke, M., Horton, S., Poland, F., Hooper, L., Song, F., Systematic overview of economic evaluations of healthrelated rehabilitation, Disability and Health Journal, Vol. 9, No. 1, pp. 11-25, 2016.

[23] Cullen, J. C., Silverstein, B. A., Foley, M. P., Linking biomechanical workload and organizational practices to burnout and satisfaction, Journal of Business and Psychology, Vol. 23, No. 1-2, pp. 63-71, 2008.

[24] Lefever, M., Decuman, S., Perl, F., Braeckman, L., Van de Velde, D., The efficacy and efficiency of Disability Management in job-retention and job-reintegration. A systematic review, Work, Vol. 59, No. 4, pp. 501-534, 2018.

[25] Miethlich, B., Slahor, L., Employment of persons with disabilities as a corporate social responsibility initiative: Necessity and variants of implementation, Proceedings of 6th CBU International Conference, March, 2018. 
[26] Wiggett-Barnard, C., Swartz, L., What facilitates the entry of persons with disabilities into South African companies?. Disability and Rehabilitation, Vol. 34, No. 12, pp. 1016-1023, 2012.

[27] Selander, J., Marnetoft, S. U., Bergroth, A., Ekholm, J., Return to work following vocational rehabilitation for neck, back and shoulder problems: risk factors review, Disability and Rehabilitation, Vol. 24, No. 14, pp. 704712, 2016.

[28] Millington, M. J., Miller, D. M., Asner-Self, K. K., Linkowski, D., Work and disability, Austin, PRO-ED, 2003, 317-342.

[29] Miethlich, B., Slahor, L., Creating shared value through implementing vocational rehabilitation in the corporate social responsibility strategy: A literature review, Proceedings of 32st IBIMA Conference, November, 2018.

[30] Csillag, S., Gyori, Z., "Is there a place for me?" Employment of people with disabilities as part of csr strategy, Proceedings of 4th Strategica Conference, pp. 860-872, October, 2016.

[31] Dean, D. H., Costs and benefits of vocational rehabilitation: An employer's perspective, Employment Relations Today, Vol. 15, No. 2, pp. 141-147, 1988.

[32] Wagner, S., Harder, H., Scott, L., Buys, N., Yu, I., Geisen, T., Randall, C., Lo, K., Tang, D., Fraess-Phillips, A., Hassler, B., Canadian Employee Perspectives on Disability Management, International Journal of Disability Management, Vol. 12, 2017.

[33] Houtenville, A., Kalargyrou, V., Employers' perspectives about employing people with disabilities: A comparative study across industries. Cornell Hospitality Quarterly, Vol. 56, No. 2, pp. 168-179, 2015.

[34] Kalargyrou, V., People with disabilities: A new model of productive labor, Proceedings of 2nd Advances in Hospitality and Tourism Marketing \& Management Conference, 2012.

[35] Houtenville, A., Kalargyrou, V., PWD: Employers' perspectives on recruitment practices, strategies, and challenges in leisure and hospitality, Cornell Hospitality Quarterly, Vol. 53, No. 1, pp. 40-52, 2012.

[36] Ball, P., Monaco, G., Schmeling, J., Schartz, H., Blanck, P., Disability as diversity in fortune 100 companies, Behavioral Sciences and the Law, Vol. 23, No. 1, pp. 97-122, 2005.

[37] Csillag, S., Gyori, Z., Matolay, R., The Critical State of Corporate Social Responsibility in Europe, Bingley, Emerald Publishing Limited, 2018, 57-81.

[38] Kuznetsova, Y., Inclusive corporate culture and employment of persons with disabilities: analysis of CSR strategies of multinational enterprises in Norway and the UK, Proceedings of UFHRD Conference, 2012.

[39] Sandler, L. A., Blanck, P., The quest to make accessibility a corporate article of faith at Microsoft: case study of corporate culture and human resource dimensions, Behavioral sciences \& the law, Vol. 23, No. 1, pp. 39-64, 2005. 